\title{
Experiment evidence on the temperature dependence of desiccation cracking behavior of clayey soils
}

Chao-Sheng Tang ${ }^{1,2}$, Yu-Jun Cui ${ }^{2 *}$, Anh-Minh Tang ${ }^{2}$, Bin Shi ${ }^{1}$,

${ }^{1}$ School of Earth Sciences and Engineering, Nanjing University, 22 Hankou Road, Nanjing 210093, China

${ }^{2}$ Ecole des Ponts - ParisTech, UR Navier-CERMES, 6 et 8, avenue Blaise Pascal, Cité Descartes, Champs-sur-Marne, 77455 Marne-la-Vallée CEDEX 2, France.

* Corresponding author

Email of authors :

Chao-Sheng Tang: tangchaosheng @ nju.edu.cn

Yu-Jun Cui: cui @ cermes.enpc.fr

Anh-Minh Tang : tang@cermes.enpc.fr

Bin Shi: shibin@nju.edu.cn 
Abstract: When drying a clayey soil, shrinkage and then cracking on soil surface occur due to water loss by evaporation, this phenomenon seems to be temperature dependent. In the present work, experimental tests were conducted on saturated slurry to investigate the desiccation cracking behavior at three temperatures (22, 60 and 105 $\left.{ }^{\circ} \mathrm{C}\right)$. The initiation and propagation of desiccation cracks during drying was monitored using a digital camera. By applying computer image processing technique, the surface crack ratio $\left(R_{S C}\right)$ which is the ratio of the surface area of cracks to the total surface area of specimen, was defined to quantify crack networks at different water contents. The experimental results show that the initial critical water content $\left(w_{I C}\right)$, which corresponds to the initiation of desiccation crack, increases with temperature rise. After the initiation of a crack, the ratio $R_{S C}$ increases with decreasing water content and then keeps almost constant when the water content becomes lower than the critical water content $\left(w_{F C}\right)$. By comparing the cracking curve with shrinkage curve, it has been found that the cracking curve, to some extent, reflects the shrinkage properties of soil since the $w_{F C}$ is related to the shrinkage limit and slightly influenced by temperature.

Key words: Romainville clay, temperature, water content, desiccation cracking, shrinkage, crack pattern. 


\section{Introduction}

It is natural phenomenon that cracks develop in clayey soils as they shrink upon drying. Better understanding the soil cracking process is essential in analyzing drought effects on buildings, because the presence of cracks changes soil surface properties and significantly modifies both the water infiltration and evaporation patterns. On the other hand, in geological, environmental and geotechnical engineering fields, clay-rich soils are widely used in constructing low-hydraulic-conductivity buffers, liners and covers for waste repository and mine tailings dams. The desiccation cracks developed in these structures are governing factors for their hydraulic properties; water conductivity is drastically increased by cracking, leading to dysfunction of the barrier systems. Albrecht and Benson (2001) found that the hydraulic conductivity of some clay liner materials caused by desiccation cracks was almost 500 times that of intact soil. The experiments of Boynton and Daniel (1985) and Rayhani et al. (2007) showed that soil cracking increases the hydraulic conductivity of several orders of magnitude. In addition, these cracks induced by shrinkage also create weak zones in a soil body with reduced overall mechanical strength and bearing capacity, and increased compressibility. The desiccation cracks were also observed in natural expansive soil slopes and vertical cuttings, considerably affecting their stability (Bagge, 1985; Silvestri et al., 1992). In the case of earth dam, the presence of crack may also turn into piping leaks, leading to dam failures as for the Stockton and Wister dams (Sherard, 1973). In the agricultural field, as desiccation cracks control the rate and velocity at which water, solutes and micro-organisms are transported in the soil, they can significantly affect the crops growth and production (Bronswijk et al., 1995; Kelly and Pomes, 1998).

The non-exhaustive applications mentioned above explains the large attention paid by researchers and scientists to the desiccation cracking phenomenon for clayey soils (Lau, 1987; Montgomery and Parsons, 1990; Corser and Cranston, 1991; Morris et al., 1992; Abu-Hejleh and Znidarcic, 1995; Konrad and Ayad, 1997a, 1997b; Ayad et al., 1997; Miller et al., 1998; Yesiller et al., 2000; Péron et al, 2006; Prat et al., 2006; Nahlawi and Kodikara, 2006).

Basically, shrinkage is mainly due to water loss by evaporation. If drying proceeds from the surface downwards to the deeper soil, the dehydrated surface layer shrinks first and thereby results in tensile stress in the surface layer. Corte and Higashi (1960) pointed out that desiccation macro-crack is likely to occur if the soil shrinkage is constrained or the tensile stress generated reaches the soil tensile strength. However, as soil is a highly complex material, its desiccation cracking behavior is governed by a large number of factors such as mineral composition, clay content, relative humidity, layer thickness and size, boundary conditions, etc. (Fang, 1997; Albrecht and Benson, 2001; Nahlawi and Kodikara, 2006; Prat et al., 2006; Lakshmikantha et al., 2006; Rodríguez et al., 2007; Tang et al., 2007). Even though many works have been focused on this issue, the essential mechanism of desiccation cracking is still not well understood. To common knowledge, the water content or water loss is the key parameter that controls the cracks initiation and propagation. On the other hand, for a 
given soil, the water loss or evaporation rate is strongly dependent on temperature and relative humidity.

This paper presents the results from laboratory experiments conducted on Romainville clay from a slurry state to investigate the shrinkage and desiccation cracking behavior at different temperatures. Image processing technique was applied to characterize the crack pattern. Surface crack ratio $\left(R_{S C}\right)$, which is the ratio of the surface cracks area to the total surface area of a specimen, was determined at different water contents to quantify the cracking extent on the soil surface. Some critical water contents during drying were identified. In addition, the relationship between cracking behavior and shrinkage properties were discussed.

\section{Material and method}

Romainville clay was used in this investigation. It was taken from the East of Paris. The physical properties are presented in Table 1 . The clay minerals are illite and smectite; the large liquid limit (77\%) and plasticity index (37) reflects the expansive behavior of this clay. Indeed, according to the Casagrande's classification criterion, the soil is a high plasticity clay. It belongs to $\mathrm{CH}$ group following the unified soil classification system (USCS). The highly plastic behavior of the soil shows that the fraction of smectite, even tough not dominant compared to illite, play an important role in the overall behavior. The natural Romainville clay was air-dried, grounded and passed through $2 \mathrm{~mm}$ sieve. Over-saturated slurry specimens were prepared by mixing soil powder with distilled water at a water content of about $170 \%$. The obtained slurry was energetically hand-mixed; and then a desired slurry quantity was poured into glass cups (117 $\mathrm{mm}$ in diameter). To remove entrapped air bubbles in soil slurry, these cups were placed on a vibration device for 5 minutes. Finally, the cups containing prepared slurry samples were covered for 24 hours. The final settled slurry thickness was about $10 \mathrm{~mm}$.

Nine specimens were prepared for drying tests at three temperatures. Three specimens were exposed to drying in room temperature $\left(22 \pm 1{ }^{\circ} \mathrm{C}, 55 \pm 5 \%\right.$ of relative humidity, $R H)$, three specimens were placed in an oven with temperature controlled at $60{ }^{\circ} \mathrm{C}(5 \pm 2 \% R H)$ and three others at $105{ }^{\circ} \mathrm{C}(0 \% R H)$. Note that the fan of the oven was stopped during drying. Along the tests, the specimens were weighed to an accuracy of $0.01 \mathrm{~g}$ to record the water loss at varying intervals, for the determination of water content changes. As the water distribution was normally heterogeneous during the evaporation process despite the small thickness of the specimens, the measured water contents correspond actually to average values. At the same time, a digital camera was fixed above the specimens to monitor crack patterns that were analyzed using image processing technique to determine the $R_{\mathrm{CS}}$ at different water contents. Figure 1 presents the schematic set-up used. Note that for the tests performed at high temperatures $\left(60\right.$ and $\left.105^{\circ} \mathrm{C}\right)$, the specimens were moved out from the oven for weighing and picturing. Much attention was paid to this procedure: it was finished in less than 15 seconds so as to minimize the effects of environmental temperature variations. 
To investigate the volume shrinkage properties under room temperature, four other specimens were prepared following the same procedure mentioned above. During drying, small soil clods were taken from the four specimens at different drying intervals to determine their water contents and densities. The clod volume used for the density determination was measured by immersing it in a non-wetting hydrocarbon liquid. According to the specific gravity presented in Table 1 and the obtained water content and density, the void ratio and the corresponding degree of saturation of specimens were calculated. For the specimens dried at high temperatures (60 and 105 ${ }^{\circ} \mathrm{C}$ ), the final void ratio was determined after cooled to room temperature.

The procedure of digital image processing is shown in Figure 2 (see also Tang et al., 2008; Liu et al., 2008). Firstly, the color photograph of the crack pattern was changed to a grey image (Figure 2a); secondly, the grey image was segmented into cracks and aggregates by binarisation, which results in binary black and white image (Figure 2b). It can be seen that the black areas represent the cracks network, and the white areas represent the aggregates. Therefore, the $R_{S C}$ can be determined by counting pixels based on the binary crack pattern.

\section{Results}

Figure 3a shows the change in water content with time for all specimens. Note that all tests started from an initial water content of about $170 \%$. Upon drying, the water content firstly decreased linearly and finally reached stabilisation, showing that the water evaporation rate was approximately constant for all specimens in the beginning of drying, and then began to slow down after a period of time and finally fell to zero. More than 4000 min was needed for specimens to reach stabilisation when dried at room temperature (about $22^{\circ} \mathrm{C}$ ); this is about 13 times that for specimens at $60^{\circ} \mathrm{C}$ and $105{ }^{\circ} \mathrm{C}$. After reaching stabilisation, the remaining water content was higher at lower temperature: $4.5 \%$ at $22^{\circ} \mathrm{C}, 0.6 \%$ at $60^{\circ} \mathrm{C}$ and 0 at $105^{\circ} \mathrm{C}$. From the recorded data

shown in Figure 3a, the initial average evaporation rate was evaluated and the results are shown in Figure 3b. A significant temperature effect was evidenced: the initial average evaporation rate was $0.02 \mathrm{~g} / \mathrm{min}$ at $22^{\circ} \mathrm{C}, 0.25 \mathrm{~g} / \mathrm{min}$ at $60^{\circ} \mathrm{C}$ and $0.50 \mathrm{~g} / \mathrm{min}$ at $105^{\circ} \mathrm{C}$.

Figure 4 depicts the relationship between $R_{S C}$ and water content $(w)$ at different temperatures. It can be observed that $R_{S C}$ increased quickly with decreasing $w$ in the early stage of cracking. By contrast, with further drying, the increment of $R_{S C}$ decreased quickly once $w$ was lower than a specific value. From the $R_{S C}-w$ curve, the following two parameters can be identified: the initial critical water content $\left(w_{I C}\right)$ which corresponds to the initiation of desiccation cracking, and the final critical water content $\left(w_{F C}\right)$ which corresponds to the transition point where $R_{S C}$ trends to stable value. These two parameters were determined as follows: $w_{I C}$ was determined by weighing the specimen once the first crack was observed on the specimen surface; $w_{F C}$ was estimated as the intersection of two lines as shown in Figure 4: (i) the regression line obtained from the last three points on the cracking curve, and (ii) the regression 
line determined by the four or five points before the highest curvature segment on the cracking curve. In addition, Figure 4 also shows that the $R_{S C}$ was larger at higher temperature at a given water content: the final $R_{S C}$ values were about 22,17 and $14 \%$ for the specimens at 105,60 and $22{ }^{\circ} \mathrm{C}$ respectively.

The effects of temperature on $w_{I C}$ and $w_{F C}$ are shown in Figure 5. It can be seen that $w_{F C}$ was not significantly affected by temperature; at 22,60 and $105^{\circ} \mathrm{C}$, the average $w_{F C}$ values were $12.5,11.4$ and $10.3 \%$ respectively. By contrast, temperature showed a significant effect on $w_{I C}$; when the temperature increased from 22 to $105{ }^{\circ} \mathrm{C}$, the average $w_{I C}$ value increased from 38.0 to $90.9 \%$. The corresponding desiccation time to initiate the first crack was also temperature-dependent: it decreased with temperature increase. In this investigation, the first crack was observed only after about 145 and 60 minutes for the specimens dried at 60 and $105{ }^{\circ} \mathrm{C}$, respectively; nearly 2 days was needed for the specimens dried at $22^{\circ} \mathrm{C}$.

The variations of void ratio and degree of saturation at room temperature $\left(22^{\circ} \mathrm{C}\right)$ are shown in Figure 6. It can be seen that the void ratio decreased linearly with decreasing water content till the water content was approximately $17 \%$. Once the water content reached this value, commonly called air entry (AE) value, the specimens were no longer saturated. With further drying, the volume shrinkage slowed down and finally the void ratio almost reached stabilization when the water content was lower than about $12 \%$, this water content value being commonly called shrinkage limit (SL: specific water content at which further water loss does not result in any reduction of soil volume). The final values of void ratio were in the range of $0.41-0.43$ and the degree of saturation was about $25 \%$.

At different temperatures, the final void ratio at the end of drying was also evaluated. The results are presented in Figure 7 . It is observed that the final void ratio was larger at higher temperature: $e=0.43$ at $22^{\circ} \mathrm{C}, 0.46$ at $60^{\circ} \mathrm{C}$, and 0.47 at $105^{\circ} \mathrm{C}$. A summary of the results for each test is made in Table 2.

\section{Discussions}

\section{Initiation of desiccation crack}

When an initially saturated soil is under drying conditions, water-air menisci start to occur at the soil surface. As a result, capillary suction in the upper layer is developed. This capillary suction engenders first an arrangement of soil particles and thus a significant volume change. Note that during this process, the soil is remaining saturated. When a certain degree of consolidation is reached, this soil particles arrangement stops and with further water evaporation, air starts to enter the deeper layer of the soil: the air entry value that corresponds to the water content at this moment is reached. From the particle level, one can imagine that each particle in the surface layer is subjected to a tensile stress induced by the developed capillary suction. Obviously, this tensile stress is increasing when water evaporation proceeds. Once the tensile stress exceeds the tensile strength of the soil, desiccation cracks occur. Note that soil tensile strength increases with suction increase (Zeh and Witt, 2007; Morris et al., 2007). 
To a certain extent, soil microstructure always shows certain heterogeneity even for slurry specimens. Thus, the bonding strength between soil particles is not uniform. Under the effect of the tensile stress, the weak zones with lower bonding strength fall in failure first. That is why cracks usually initiate at soil surface defects (Zabat et al., 1997; Weinberger, 1999). Therefore, the critical soil tensile strength for cracking onset reflects the local mechanical properties of the weakest zone. This tensile strength must be different from that measurement in a macroscopic level.

It has been observed in Figure 2 that the crack segments are almost perpendicular one to another and the intersection angles are generally equal to 90 degree; the crack network is mainly composed of square pattern. This observation can be explained based on the maximum stress release criterion and crack propagation criterion (Lachenbruch, 1962; Morris et al., 1992). Because the internal tensile stress perpendicular to the existing crack plane has been released already, the direction of the maximum tensile stress on the tip of a propagating crack must be parallel to the plane of the existing crack. The propagation of the desiccation crack is thus gradually turned towards the preexisting crack until they finally intersect at right angles. Note however that in field conditions, the crack pattern is in general not as regular as that observed in laboratory conditions. This is mainly because the field soils are much more heterogeneous and moreover they are conditioned by various environmental factors such as the variable climatic conditions and the presence of surface vegetation cover. The water evaporation and suction developed are therefore not uniform.

Tang et al. (2008) investigated the effect of wetting-drying cycles on soil crack pattern in laboratory conditions, and found that the cracks were becoming more irregular with increasing number of wetting-drying cycles. They also attributed this phenomenon to the decreasing homogeneity of the soil specimen.

\section{Temperature dependence of water evaporation rate}

The rate and duration of water evaporation depends on various factors such as temperature, relative humidity, wind velocity, solar radiation, soil suction, salt concentration, soil pore size and layer thickness, etc. (Kayyal, 1995; Cui et al., 2005 ; Prat et al., 2006; Rodríguez et al., 2007). At a higher temperature, the water molecule motion velocity and kinetic energy is higher, and the viscosity, the interfacial tension of water and the water retention capacity of soil are lower (Tang and Cui, 2005). Therefore, soil water molecules escape more easily to the atmosphere at a higher temperature, resulting in a higher water loss rate. Nevertheless, the temperature itself cannot be regarded as the unique variable controlling water evaporation rate in this investigation. Indeed, according to Kelvin law, a higher temperature corresponds to a lower relative humidity. In other words, at a higher temperature, the relative humidity gradient between soil surface and the upper air layer (namely the vapor pressure gradient across soil-air interface) is higher. This can equally explain the higher evaporation rate observed at higher temperatures.

With further drying, the water evaporation rates of all the soil specimens decreased and finally fell to zero. This observation is in agreement with that made by Wilson et al. (1997) who conducted evaporation tests on three different soil samples, and can be 
related to three factors: (i) the availability of water in soil specimens decreased with time; (ii) the developed high suction bounded the water molecules and prevented them from escaping to the atmosphere; (iii) the vapor pressure gradient across soil-air interface decreased with drying.

\section{Temperature dependence of desiccation cracking behavior}

As discussed above, desiccation cracking is mainly governed by soil suction and tensile strength; when the tensile stress induced by suction increase exceeds the tensile strength, cracks occur. Unfortunately, unlike the temperature effects on compressive shear strength (see for instance Michell, 1964; Cui et al., 2000; Villar and Lloret, 2004), to the authors' knowledge, the temperature effects on the tensile strength have been not studied. Previous results showed that soil shear strength in general decreases with temperature (Michell, 1964; Cui et al., 2000); this leads to expect a decrease of tensile strength with temperature increase. As far as the suction change is concerned, as indicated by Kayyal et al. (1995), the rate of suction increase is directly related to the evaporation rate. Therefore, at higher temperature, a higher suction increase rate can be expected. As a result, the induced surface tensile stress can exceed the tensile strength of grains in shorter time. To sum up, the earlier desiccation cracks observed in Figures 3 and 4 at higher temperatures can be attribute to both higher suction increase rate and lower tensile strength.

As mentioned above, cracking begins from the surface to deeper soil. At higher temperature, desiccation cracks initiates faster in the surface layer, and only a limited amount of water in the lower layer can be transported to the surface layer before the cracks initiation because of the generally low permeability of clayey soils. This would lead to a higher initial critical water content $w_{I C}$. Furthermore, if the soil tensile is decreased by temperature rise, cracking would occur at lower suction or higher water content. This is another reason for the $w_{I C}$ increase with temperature as observed in Figure 5.

At crack initiation, the degree of saturation may almost equal to one, but close to the air entry point (Simpkins et al., 1989; Péron et al., 2006; Rodríguez et al., 2007). The results in Figure 5 show that the $w_{I C}$ of specimens drying under any temperature is much higher than the AE value (17\%, see Figure 6). This suggests that there is a significant difference between the present experimental $w_{I C}$ and the values reportedby the authors above. One of the possible reasons is that the measured $w_{I C}$ was an average water content value. As shown earlier, evaporation begins at soil surface and goes downwards to deeper soil. Water content distribution in the soil was therefore not uniform, and increased with soil depth. When the upper layer became unsaturated and desiccation cracks were initiated in it, the lower layer was still at higher degree of saturation. As a result, the herein measured $w_{I C}$ is much higher than both the actual local water content in upper layer and the theoretical $\mathrm{AE}$ value determined from the shrinkage curve. Nahlawi and Kodikara (2006) also highlighted that $w_{I C}$ generally increases as soil layer thickness increases. Actually, it is very difficult to find a suitable technique to monitor the actual changes of water content in upper layer. Moreover, it is also difficult to determine the exact position of the interface between 
the upper and lower layer, because in microscopic scale, the thickness of upper layer at the beginning of cracking may be composed of only several clay sheets. In order to ensure a satisfactory accuracy in determining $w_{I C}$, the simplest way is to decrease the sample thickness. In theory, if the specimen is thin enough, relative uniform water distribution would be obtained during drying, then the measured $w_{I C}$, would be much closer to the theoretical AE value. In spite of the technical drawback of the adopted method related to the accuracy in determining $w_{I C}$, it is believed that the value of $w_{I C}$ determined by averaging the water content over the thickness of $10 \mathrm{~mm}$ allows satisfactory characterization of the temperature effect on soil cracking, at least for engineering practice.

\section{Soil shrinkage and soil cracking}

During drying, the decrease in water content is largely accompanied by the arrangement of soil particles. The formed crack space is a fraction of the shrunk pore volume and reflects the shrinkage magnitude. When the water content reached the soil shrinkage limit, the soil particles almost reached their densest configuration and the pore volume remained unchanged with further water loss (Krisdani et al. 2008). Accordingly, the cracks propagation also trended to finish at this critical water content. This phenomenon is clearly shown in Figures 4 and 6: both $R_{S C}$ and void ratio reached stabilization when water content was lower than either $w_{F C}$ or shrinkage limit (SL). The values of $w_{F C}$ (Figure 5) and SL (Figure 6) at room temperature are close, suggesting that the cracking curves shown in Figure 4, to some extent, characterize the soil shrinkage behavior. In other words, there is a correlation between $w_{F C}$ and SL.

The results in Figure 4 show that $R_{S C}$ depends significantly on temperature: (i) at a same water content, the higher the temperature the larger the value of $R_{S C}$, (ii) at the end of drying, a larger $R_{S C}$ was also obtained for the specimen dried at higher temperature. Actually, as shown in the previous sections, $R_{S C}$ is directly related to the soil shrinkage properties; and moreover, the shrinkage and cracking are both caused by the developed suction during desiccation. Kayyal et al. (1995) indicated that a higher evaporation rate results in a higher suction increase rate. As temperature rise increases the evaporation rate, the suction developed in the soil must be higher at higher temperatures, engendering larger shrinkage and more cracks or larger value of $R_{S C}$

\section{Conclusions}

Desiccation cracking was investigated on Romainville clay taken from the east of Paris. Soil water evaporation, extent of cracking and soil shrinkage at various temperatures were analyzed. The following conclusions can be drawn.

i) Water evaporation rate increases with temperature, and at a given temperature two water loss stages can be identified during drying: a constant rate zone where water loss occurs at constant rate and a decreasing rate zone.

ii) The surface crack ratio $R_{S C}$ increases with increasing temperature. The $R_{S C}$ increases quickly with decreasing water content after the initiation of crack, and 
then reaches a stabilized value.

iii) The formed crack space corresponds to the pore volume shrinkage. The cracking curve ( $R_{S C}$ versus water content), to some extent, reflects the shrinkage properties of soil: the larger the soil shrinkage, the larger the value of $R_{S C}$.

iv) For an open soil specimen, drying or evaporation usually results in non-uniform water distribution in the soil. The upper layer becomes unsaturated first and desiccation cracks are initiated. The initial critical water content $\left(w_{I C}\right)$ determined by averaging over the whole thickness increases with temperature and is much higher than the air entry (AE) point determined from the shrinkage curve.

v) The final critical water content $\left(w_{F C}\right)$ determined from cracking curve can be correlated to shrinkage limit (SL) and slightly influenced by temperature.

\section{Acknowledgements}

This work was supported by the State Key Program of National Natural Science of China (Grant No. 40730739) and the Research Fund for the Doctoral Program of Higher Education of China (Grant No. 20090091120037). It was performed within the projet ANR-RGCU «Analyse du Retrait-Gonflement et de ses Incidences sur les Constructions »- ARGIC.

\section{References}

Abu-Hejleh, A.N., Znidarcic, D., 1995. Desiccation theory for soft cohesive soils. ASCE Journal of Geotechnical Engineering 121(6), 493-502.

Albrecht, B.A., Benson, C.H., 2001. Effect of desiccation on compacted natural clay. Journal of Geotechnical and Geoenvironmental Engineering 127(1), 67-75.

Ayad, R., Konrad, J.M., Soulié, M., 1997. Desiccation of a sensitive clay: application of the model CRACK. Canadian Geotechnical Journal 34, 943-951.

Bagge, G., 1985. Tension cracks in saturated clay cuttings. Proceedings, $11^{\text {th }}$ International Conference on Soil Mechanics and Foundations Engineering, San Francisco, Vol. 2, pp. 393-395.

Bronswijk, J.J.B., Hamminga, W., Oostindie, K., 1995. Field scale solute transport in a heavy clay soil. Water Resources Research 31: 517-526.

Boynton, S.S., Daniel, D.E., 1985. Hydraulic conductivity tests on compacted clay. ASCE Journal of Geotechnical Engineering 111(4), 465-478.

Corser, P., Cranston, M., 1991. Observations on long-term performance of composite clay liners and covers. In Proceedings of Geosynthetics Design and Performance, Vancouver Geotechnical Society, Vancouver, British Columbia, Canada, pp. 16-25.

Corte, A., Higashi, A., 1960. Experimental research on desiccation cracks in soil. Research report 66, U.S. Army Snow Ice and Permafrost Research Estabilishment, Wilmette, Illinois.

Cui, Y. J., Sultan, N., Delage, P., 2000. A thermomechanical model for clays. Canadian Geotechnical Journal 37 (3), 607-620. 
Cui, Y.J., Lu, Y.F., Delage, P., Riffard, M., 2005. Field simulation of in-situ water content and temperature changes due to ground-atmospheric conditions. Géotechnique 55(7), 557-567.

Fang, H.Y., 1997. Introduction to environmental geotechnology. CRC Press, Boca Raton. FL.

Kayyal, M.K., 1995. Effect of the moisture evaporative stages on the development of shrinkage cracks in soil. In Proceedings of First International Conference on Unsaturated Soils, pp. 373-379.

Kelly, B.P., Pomes, M.L., 1998. Preferential flow and transport of nitrate and bromide in a claypan soil. Ground water 36, 484-494.

Krisdani, H., Rahardjo, H., Leong, E.C., 2008. Effects of different drying rates on shrinkage characteristics of a residual soil and soil mixtures. Engineering Geology 102, 31-37.

Konrad, J.M., Ayad, R., 1997a. An idealized framework for the analysis of cohesive soils undergoing desiccation. Canadian Geotechnical Journal 34, 477-488.

Konrad, J.M., Ayad, R., 1997b. Desiccation of sensitive clay: field experimental observations. Canadian Geotechnical Journal 34, 929-942.

Lakshmikantha, M.R., Prat, P.C., Ledesma, A., 2006. An experimental study of cracking mechanisms in drying soils. In proceedings of The $5^{\text {th }}$ ICEG Environmental Geotechnics, Thomas Telford, London, 2006.

Lachenbruch, A.H., 1962. Mechanics of thermal contraction cracks and ice-wedge polygons in permafrost. Geological Society of America, No 70. New York.

Lau, J.T.K., 1987. Desiccation cracking of clay soils. M.Sc. thesis, Department of Civil Engineering, University of Saskatchewan, Saskatoon, Canada.

Liu, C., Wang, B.J., Shi, B., Tang C.S., 2008. The analysis method of Morphological parameters of rock and soil crack based on image processing and recognition. Chinese Journal of Geotechnical Engineering 30(9), 1383-1388.

Mitchell, J.K., 1964. Shearing resistance of soils as a rate process. ASCE Journal of Soil Mechanics And Foundation, Engineering Division 90(1), 231-251

Miller, C.J., Mi, H., Yesiller, N., 1998. Experimental analysis of desiccation crack propagation in clay liners. Journal of the American Water Resources Association AWRA 34(3), 677-686.

Montgomery, R.J., Parsons, L.J., 1990. The Omega Hills cover test plot study: fourth year data summary. In Proceedings of the 22nd Mid-Atlantic Industrial Waste Conference, Drexel University, Philadelphia, USA.

Morris, P.H., Graham, J., Wiliams, D.J., 1992. Cracking in drying soils. Canadian Geotechnical Journal 29, 263-277.

Nahlawi, H., Kodikara, J.K., 2006. Laboratory experiments on desiccation cracking of thin soil layers. Geotechnical and Geological Engineering 24, 1641-1664.

Péron, H., Laloui, L., Hueckel, T., Hu, L., 2006. Experimental study of desiccation of soil. UNSAT 2006, ASCE Geotechnical Special Publication, Miller et al. eds., 147, pp. 1073-1084.

Prat, P.C., Ledesma, A., Lakshmikantha, M.R., 2006. Size effect in the cracking of drying soil. In Proceedings of the $16^{\text {th }}$ European Conference of Fracture (edited by 
E.E. Gdoutos), Springer.

Rayhani, M.H.T., Yanful, E.K., Fakher, A., 2007. Desiccation-induced cracking and its effect on the hydraulic conductivity of clayey soils from Iran. Canadian Geotechnical Journal 44, 276-283.

Rodríguez, R., Sánchez, M., Ledesma, A., Lloret, A., 2007. Experimental and numerical analysis of desiccation of a mining waste. Canadian Geotechnical Journal 44, 644-658.

Sherard, J.L., 1973. Embankment dam cracking. In Embankment-dam engineering (Casagrande Volume). John Wiley \& Sons, New York, pp. 271-353.

Silvestri, V., Sarkis, G., Bekkouche, N., Soulié, M., 1992. Evapotranspiration, trees and damage to foundations in sensitive clays. Canadian Geotechnical Conference, Vol. II, pp. 533-538.

Sitharam, T.G., Sivapullaiah, P.V., Subba-Rao, K.S., 1995. Shrinkage behaviour of compacted soils. In Proceeding of First International Conference on Unsaturated Soils, UNSAT'95, Paris, pp. 195-200.

Simpkins, P.G., Johnson, Jr., D.W., Fleming, D.A., 1989. Drying behavior of colloidal silica gels. Journal of the American Ceramic Society 72(10), 1816-1821.

Tang, A.M., Cui, Y.J., 2005. Controlling suction by the vapour equilibrium technique at different temperatures and its application in determining the water retention properties of MX80 clay. Canadian Geotechnical Journal 42, 287-296.

Tang, C.S., Shi, B., Liu, C., Wang, B.J., Gao, W., 2007. Developing law and morphological analysis of shrinkage cracks of clayey soil under different temperatures. Chinese Journal of Geotechnical Engineering 27(5), 743-749.

Tang, C., Shi, B., Liu, C., Zhao, L., Wang, B., 2008. Influencing factors of geometrical structure of surface shrinkage cracks in clayey soils, Engineering Geology 101, 204-217.

Villar, M.V., Lloret, A., 2004. Influence of temperature on the hydro-mechanical behaviour of a compacted bentonite. Applied Clay Science 26, 337-350.

Weinberger, R., 1999. Initiation and growth of cracks during desiccation of stratified muddy sediments. Journal of Structural Geology 21, 379-386.

Wilson, G.W., Fredlund, D.G., and Barbour, S.L., 1997. The effect of soil suction on evaporative fluxes from soil surfaces. Canadian Geotechnical Journal 34, 145-155.

Yesiller, N., Miller, C.J., Inci, G., and Yaldo, K., 2000. Desiccation and cracking behavior of three compacted landfill liner soils. Engineering Geology 57, 105-121.

Zabat, M., Vayer-Besançon, M., Harba, R., Bonnamy, S., Van Damme, H., 1997. Surface topography and mechanical properties of smectite films. Progress in Colloid and Polymer Science. pp. 96-102. Berlin: Springer.

Zeh, R.M., Witt, K.J., 2007. The Tensile Strength of Compacted Clays as Affected by Suction and Soil Structure. Experimental Unsaturated Soil Mechanics 112, 219-226. 


\section{Table}

Table 1 . Physical properties of Romainville clay

\begin{tabular}{ll}
\hline Soil properties & Values \\
\hline Specific gravity & 2.79 \\
Liquid limit & $77 \%$ \\
Plastic limit & $40 \%$ \\
Plasticity index & 37 \\
USCS classification & $\mathrm{CH}$ \\
Clay $(<2 \mu \mathrm{m})$ & $79 \%$ \\
Clay composition & Illite (dominated) and smectite \\
Specific surface area & $340 \mathrm{~m} / \mathrm{g}$ \\
\hline
\end{tabular}

Table 2. The summery of the results for each test at various temperatures

\begin{tabular}{llllllll}
\hline $\begin{array}{l}\text { Specimen } \\
\text { No. }\end{array}$ & $\begin{array}{l}\text { Initial } \\
\text { water } \\
\text { content } \\
(\%)\end{array}$ & $\begin{array}{l}\text { Temperature } \\
\left({ }^{\circ} \mathrm{C}\right)\end{array}$ & $\begin{array}{l}\text { Initial } \\
\text { evaporation } \\
\text { rate } \\
(\mathrm{g} / \mathrm{min})\end{array}$ & $\begin{array}{l}\text { Surface } \\
\text { crack } \\
\text { ratio } \\
R_{S C}(\%)\end{array}$ & $\begin{array}{l}\text { Initial } \\
\text { critical } \\
\text { water } \\
\text { content } \\
w_{I C}(\%)\end{array}$ & $\begin{array}{l}\text { Final } \\
\text { critical } \\
\text { water } \\
\text { content } \\
w_{F C}(\%)\end{array}$ & $\begin{array}{l}\text { Final } \\
\text { void } \\
\text { ratio }\end{array}$ \\
\hline S1 & 170 & 22 & 0.021 & 13.9 & 35.7 & 15.3 & 0.431 \\
S2 & 170 & 22 & 0.022 & 13.8 & 40.1 & 9.9 & 0.430 \\
S3 & 170 & 22 & 0.022 & 14.2 & 38.2 & 12.3 & 0.430 \\
S4 & 170 & 60 & 0.252 & 17.3 & 79.1 & 8.7 & 0.465 \\
S5 & 170 & 60 & 0.255 & 16.9 & 74.8 & 14.3 & 0.461 \\
S6 & 170 & 60 & 0.250 & 16.9 & 72.3 & 11.2 & 0.457 \\
S7 & 170 & 105 & 0.507 & 23.1 & 96.1 & 13.1 & 0.470 \\
S8 & 170 & 105 & 0.501 & 21.5 & 87.1 & 10.1 & 0.471 \\
S9 & 170 & 105 & 0.499 & 22.3 & 89.5 & 7.6 & 0.473 \\
\hline
\end{tabular}




\section{Figure captions}

Figure 1. Schematic drawing of set-up

Figure 2. Procedure of digital image processing. (a) initial grey level crack pattern, (b) binary black and white crack pattern.

Figure 3. (a) Change in water content with time during drying, (b) relationship between initial water evaporation rate and temperature.

Figure 4. Relationship between $R_{\mathrm{SC}}$ and water content.

Figure 5. Change in $w_{I C}$ and $w_{F C}$ with temperature.

Figure 6. Variations of void ratio and degree of saturation with water content for specimens dried at room temperature.

Figure 7. Change in final void ratio with temperature.
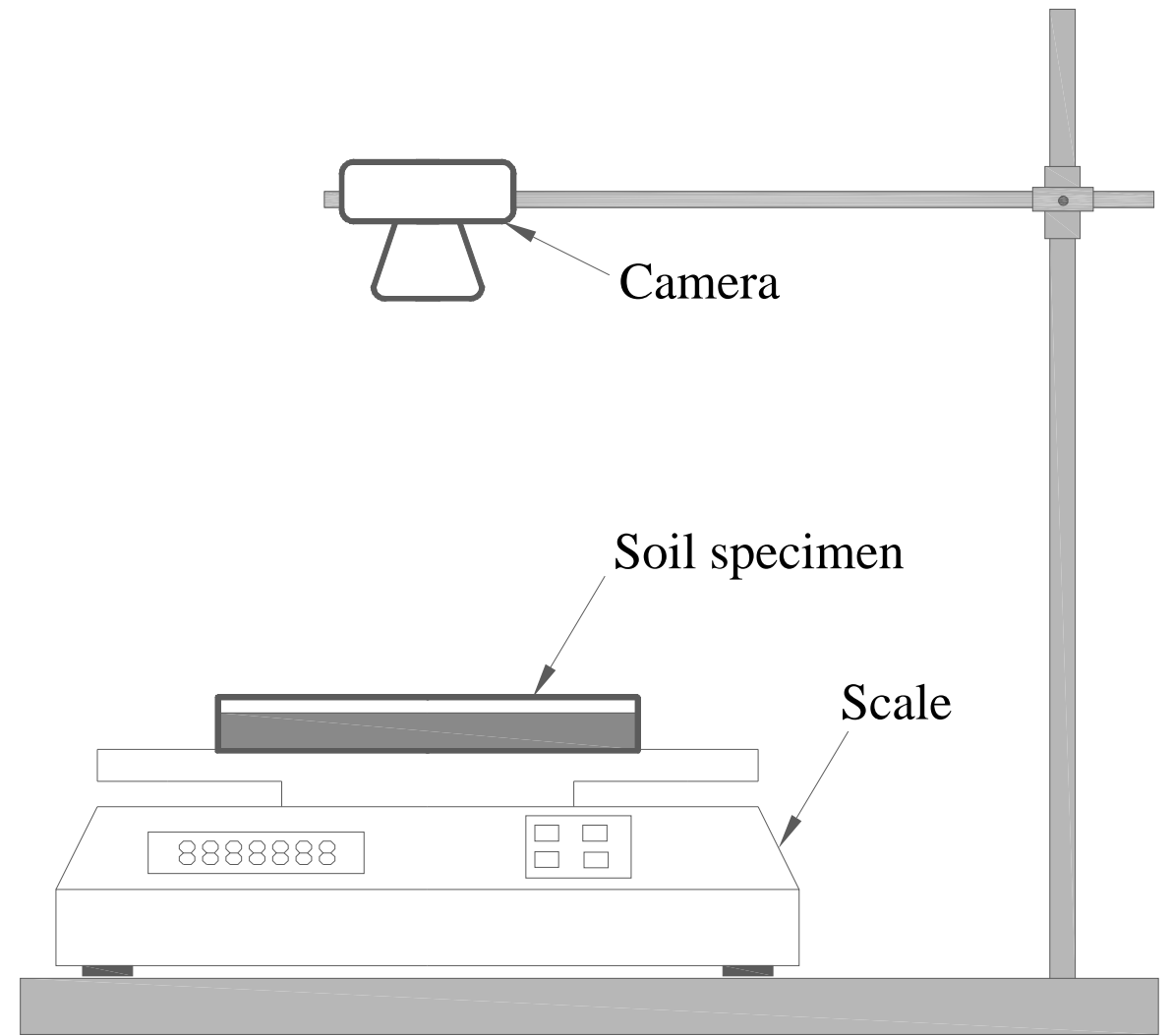

Figure 1 


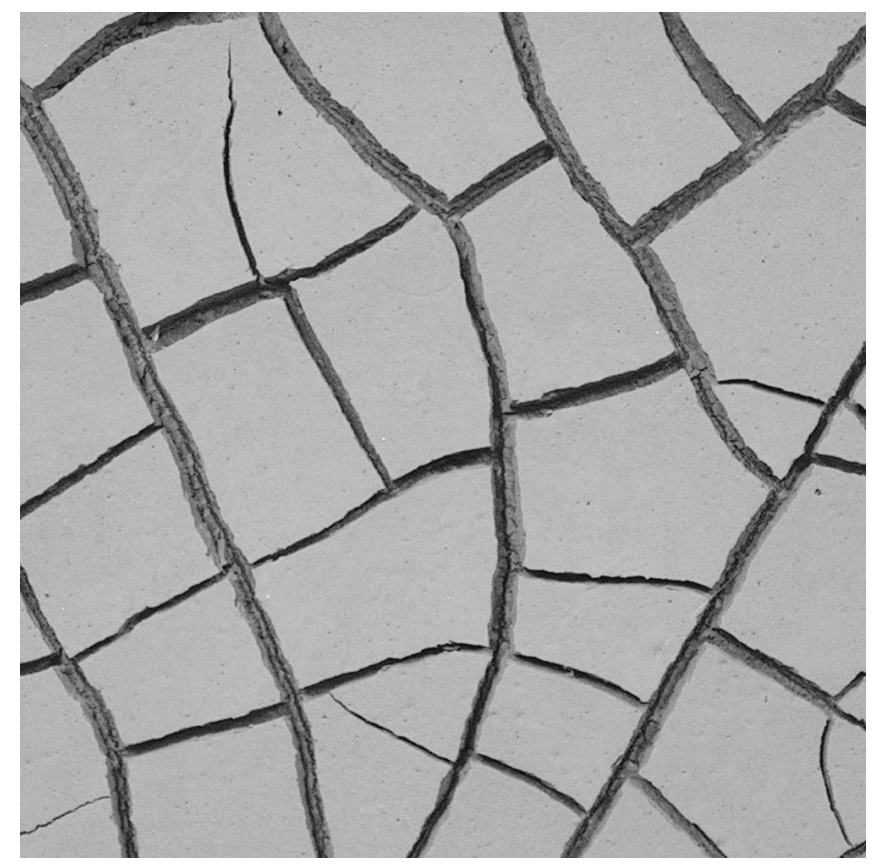

(a)

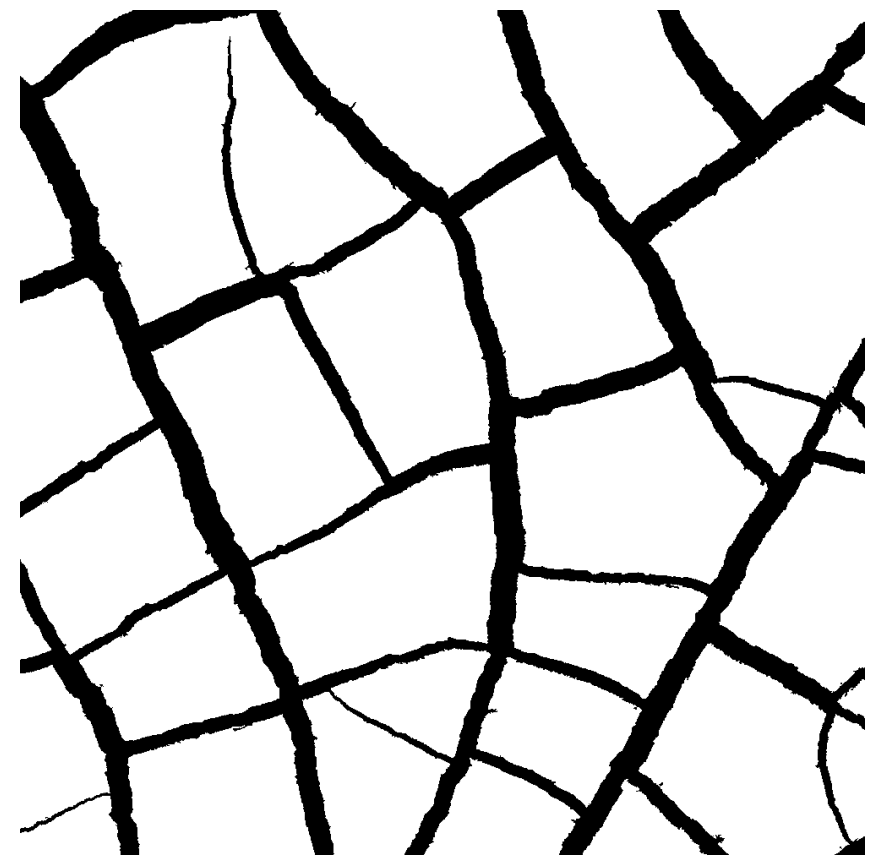

(b)

Figure 2. 


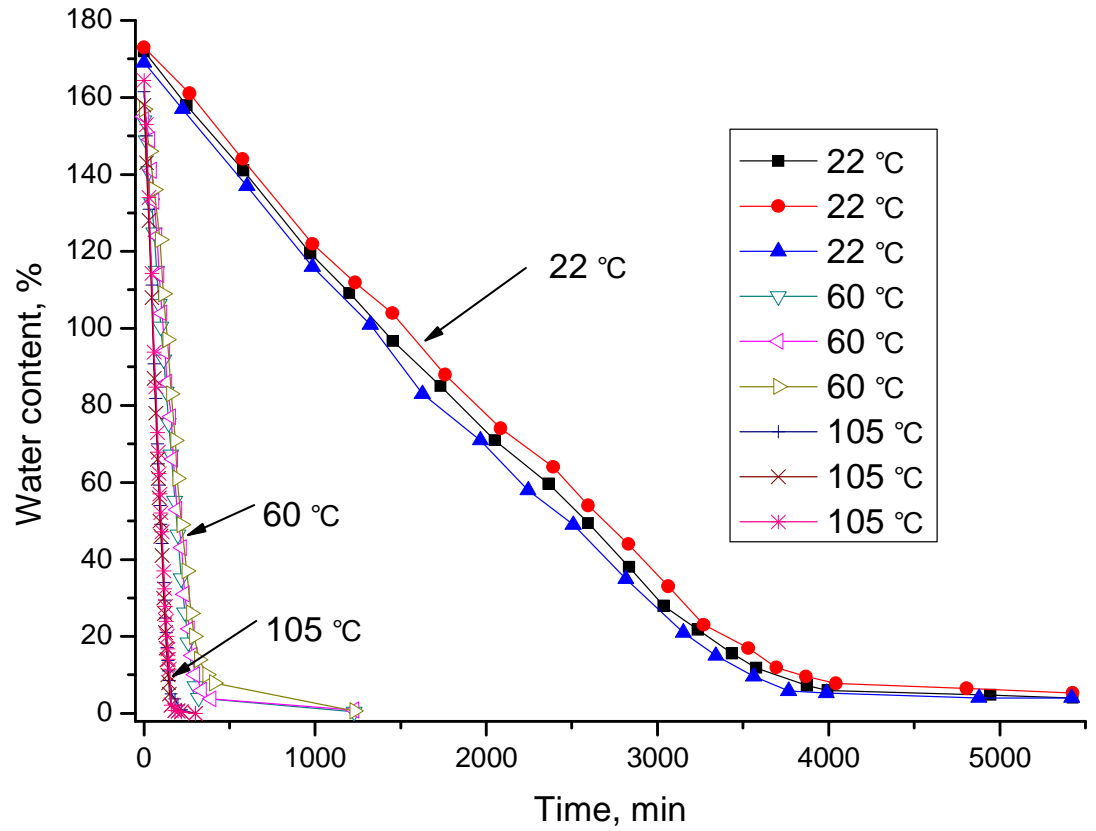

(a)

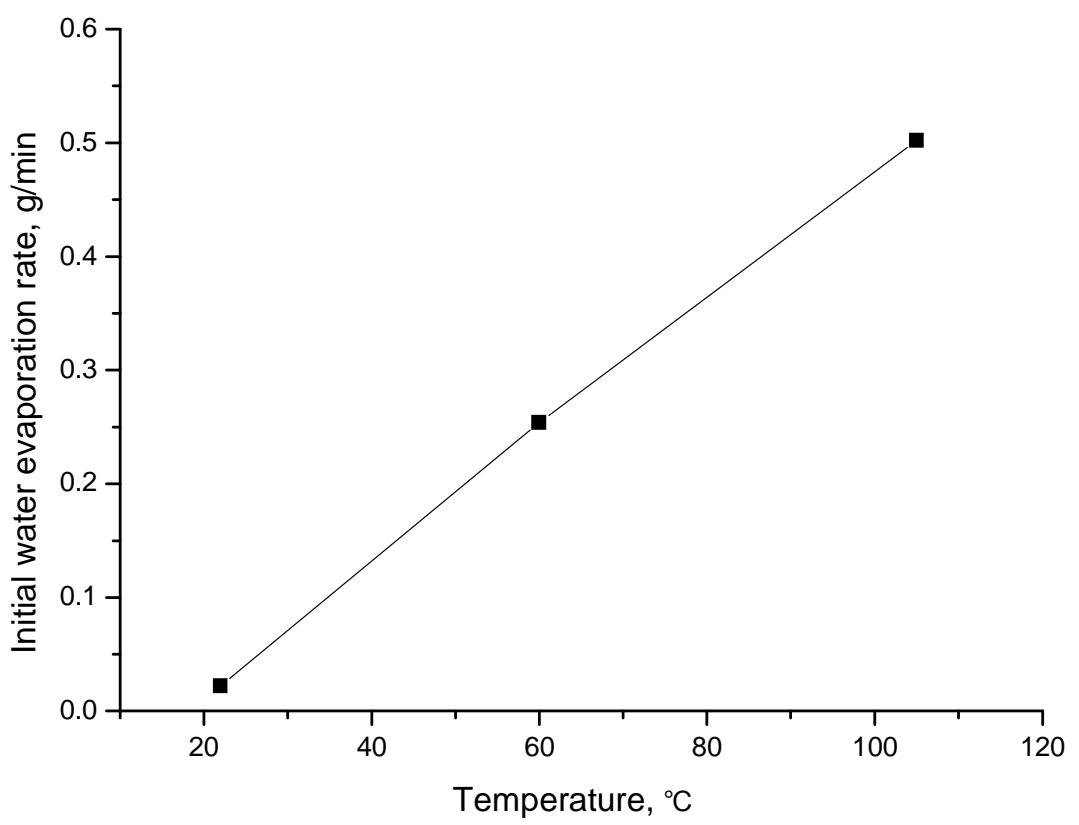

(b)

Figure 3. 


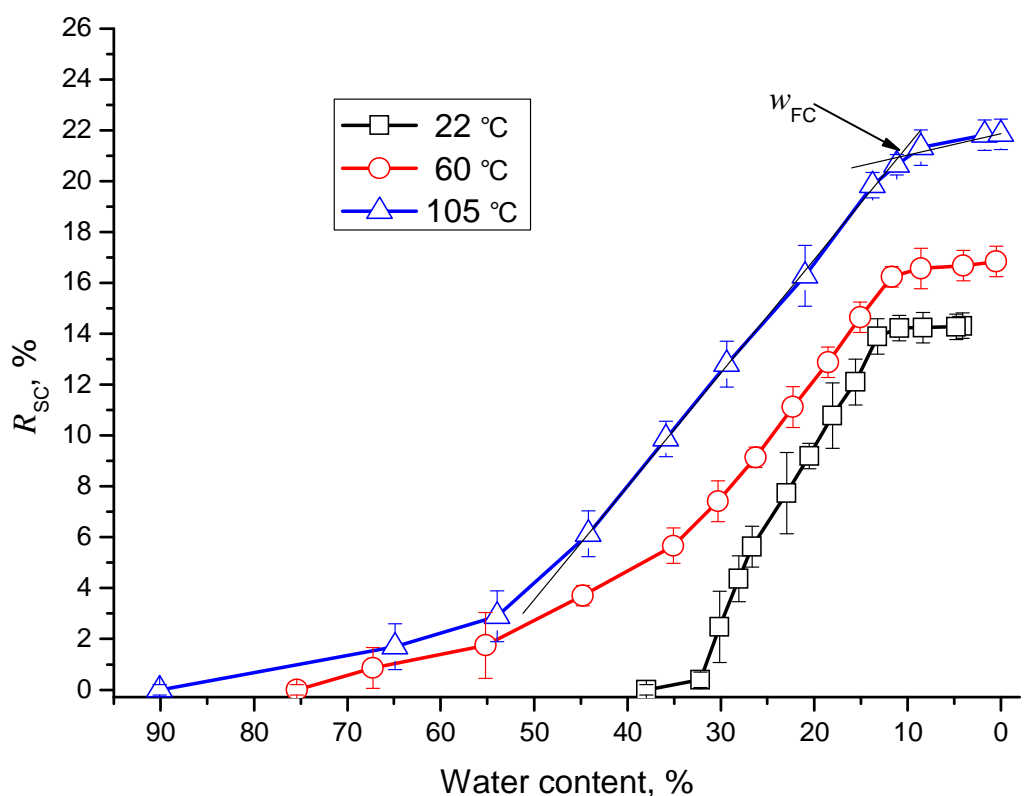

Figure 4.

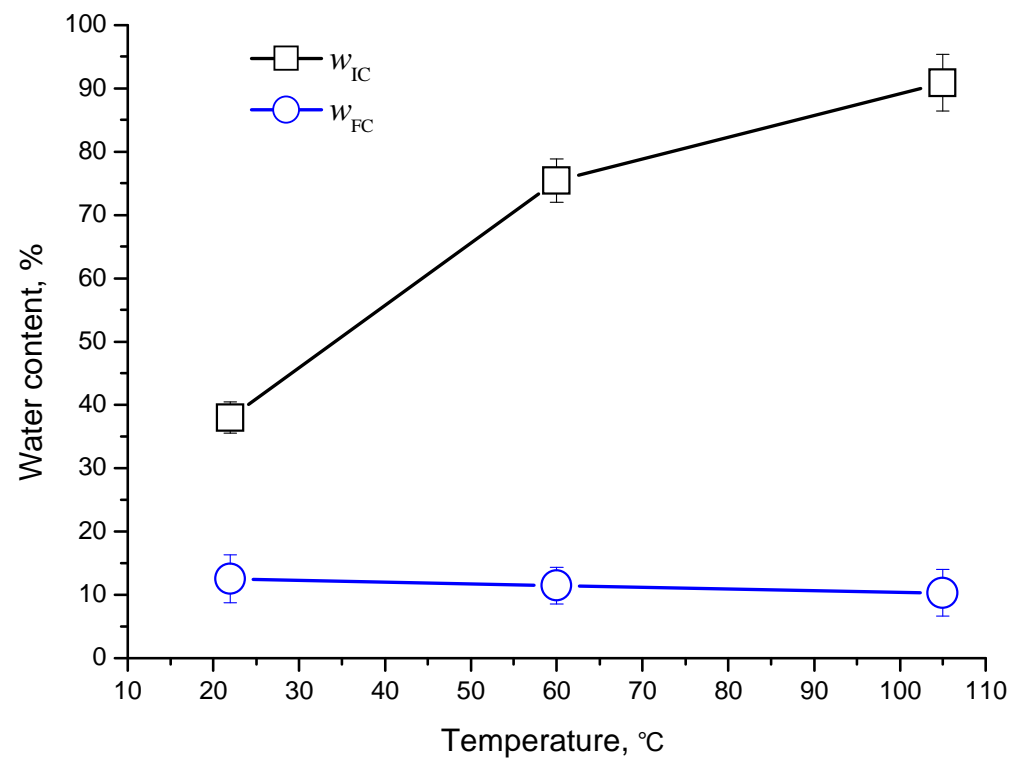

Figure 5. 


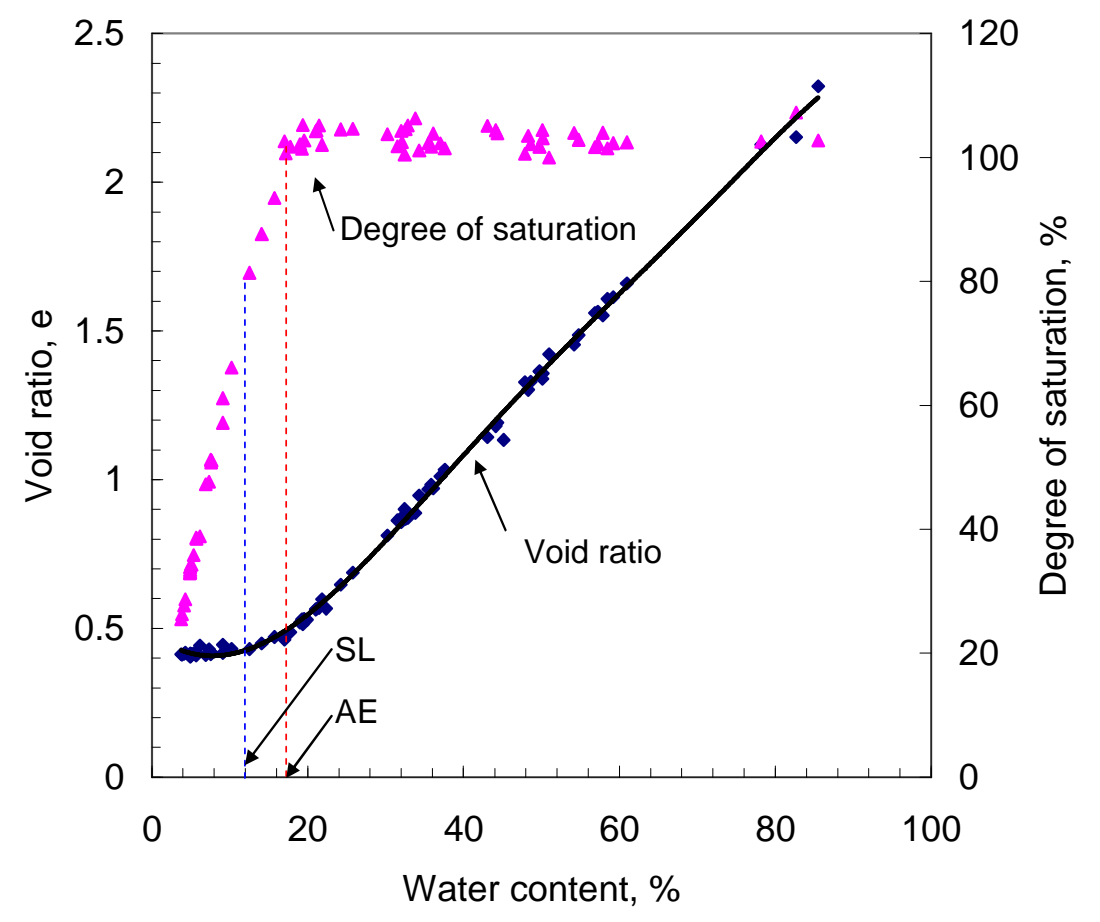

Figure 6.

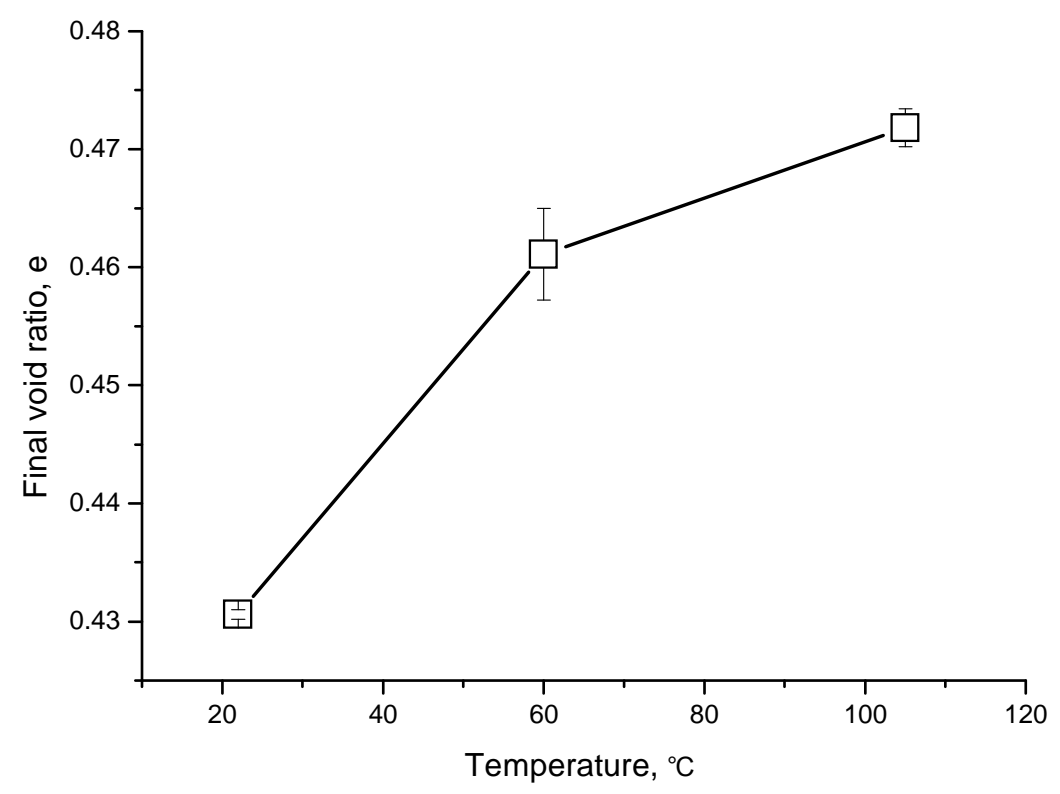

Figure 7. 